\title{
Chromatographic Behavior of Proteins on Stationary Phase with Aminocarboxy Ligand
}

\author{
Rong Li, ${ }^{*}$ Ming-Yang Ju, Bin Chen," Qing-Yuan Sun, Guo-Liang Chen, Mei Shi, Xiao-Gang Wang, and Jian-Bin Zheng ${ }^{\dagger}$ \\ School of Chemical Engineering, Northwest University, North Taibai Road 229, Xi'an 710069, P. R. China \\ *E-mail:lhr40222@tom.com \\ ${ }^{\dagger}$ Institute of Analytical Science, Northwest University, North Taibai Road 229, Xi'an 710069, P. R. China \\ Received November 2, 2010, Accepted December 8, 2010
}

\begin{abstract}
An aminocarboxy aspartic acid-bonded silica (Asp-Silica) stationary phase was synthesized using L-aspartic acid as ligand and silica gel as matrix. The standard protein mixtures were separated with prepared chromatographic column. The effects of solution $\mathrm{pH}$, salt concentration and metal ion on the retention of proteins were examined, and also compared with traditional iminodiacetic acid-bonded silica (IDA-Silica) column. The results show that Asp-Silica column exhibited an excellent separation performance for proteins. The retention of proteins on Asp-Silica stationary phase was consistent with electrostatic characteristic of cation-exchange. The stationary phase displayed typical metal chelate property after fixing copper ion (II) on Asp-Silica. Under competitive eluting condition, protein mixtures were effectively isolated. Asp ligand showed better ion-exchange and metal chelating properties as compared with IDA ligand.
\end{abstract}

Key Words: Cation-exchange, Metal chelate, Aminocarboxy ligand, Competitive elution, Protein

\section{Introduction}

Aminocarboxy is one of the commonly used stationary phase ligands for high performance liquid chromatography (HPLC). ${ }^{1-4}$ The characteristics of these ligands are: 1) aminocarboxy stationary phase without metal ion can be used as cation exchanger to separate oppositely charged protein. ${ }^{5-7}$ 2) The stationary phase with metal ion can be used to isolate protein with selective affinity for immobilized metal ion. ${ }^{8-9}$ Hence, aminocarboxy ligand has been widely used for the separation and purification of proteins.

A series of aminocarboxy ligands were explored in order to improve the selectivity and stability of chromatographic columns. The common ligands are iminodiacetic acid (IDA), nitrilotriacetic acid (NTA), N,N,N'-tris(carboxymethy)-ethylenediamine (TED), carboxymethylated aspartic acid (CM-ASP), poly-aspartic acid (PAA), etc.. Among these ligands, PAA is a commonly used ligand. ${ }^{10}$ However, PAA just can be used as an ion-exchange ligand, but not as a metal chelating ligand. In this paper, the study mainly focused on examining the characteristics of aminocarboxy-silica stationary phase with dual chromatographic functions. Another most widely used ligand is IDA. ${ }^{4,8,9,11}$ Studies show that ion-exchange property of IDA is significant and stable, but metal chelating property of IDA is unstable, especially for strong affinity column. A typical strong affinity metal chelate column is obtained if IDA column is immobilized with $\mathrm{Cu}^{2+}$. Adsorbed proteins on the column can be eluted only by adding the competitive agent with a certain concentration. ${ }^{2}$ However, the fatal defects of this approach are ineffective separation for proteins and serious leakage of $\mathrm{Cu}^{2+}$. As a result, the performance and life of the column are all diminished, and the column even can not be applied.

To improve above defects, Asp-Silica stationary phase possessing ion-exchange and metal chelating properties together was synthesized in our laboratory. Based on examining ion exchange property of Asp-Silica stationary phase, a new metal chelate stationary phase-Asp-Cu(II)-Silica was prepared through fixing $\mathrm{Cu}^{2+}$ onto the Asp-Silica stationary phase. Ion exchange and metal chelating properties of Asp ligand were compared with those of traditional IDA ligand.

\section{Experimental}

Reagents and Chemicals. Silica gel $(7 \mu \mathrm{m}, 300 \AA)$ was obtained from Lanzhou Institute of Chemical Physics of the Chinese Academy of Sciences (Lanzhou, China). $\gamma$-glycidoxypropyltrimethoxysilane ( $\gamma$-GLDP) was purchased from Gaixian Chemical Engineering Institute (Liaoning, China). L-Asp was purchased from Shanpu Chemical Engineering Company (Shanghai, China). Imidazole (Imid), glycine (Gly) and the other reagents were of analytical grade and purchased from Xi'an Chemical Reagent Company (Xi'an, China). Cytochrome-C (CytC), lysozyme (Lys) and ribonuclease (RNase) were purchased from Sigma Company (St. Louis. Mo., USA). Bovine serum albumin (BSA) was obtained from Biochemical Reagent Company (Shanghai, China). $2.0 \mathrm{mg} / \mathrm{mL}$ protein mixture of BSA, RNase, Cyt-C and Lys were prepared with $20 \mathrm{mM}$ phosphate buffer (PB, pH 6.0).

Apparatus. ÄKTA purifier 10 (Amersham Biosciences, Sweden) was used for chromatographic experiments. Atomic absorption spectrometry TAS-986 (Puxi General Apparatus Co., Ltd., China) was used for determining binding capacities and leakages of $\mathrm{Cu}^{2+}$. Potentiometer TitraMate 20 (Mettler Toledo, Switzerland) was used for adjusting the $\mathrm{pH}$ of the solutions. Slurry packed apparatus 124PP (Chemico, Japan) was used for column packing.

Synthesis of Epoxy-Activated Silica. Epoxy-activated silica was synthesized in acetate-acetic acid buffer (NaAc-HAc, $\mathrm{pH}$ 


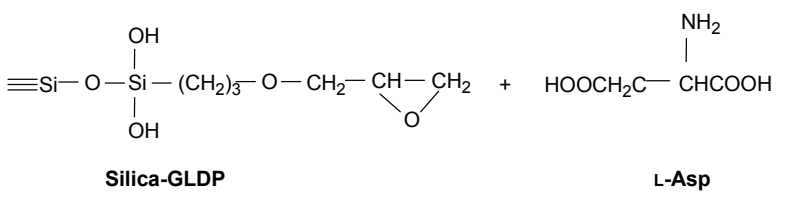

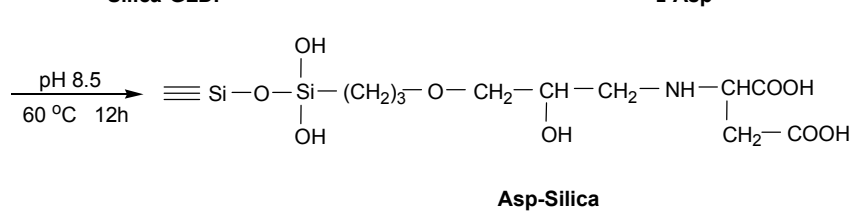

4.0) according to the procedure in reference. ${ }^{12}$

Synthesis of Asp-Silica Stationary Phase. $1.5 \mathrm{~g}$ of L-Asp was added to $30 \mathrm{~mL}$ of $1 \mathrm{M}$ sodium carbonate $\left(\mathrm{Na}_{2} \mathrm{CO}_{3}\right)$. The $\mathrm{pH}$ of the solution was adjusted to 8.5 followed by the addition of $2.0 \mathrm{~g}$ dried epoxy silica gel. The reaction was carried out at $65^{\circ} \mathrm{C}$ for $12 \mathrm{~h}$ with stirring. The obtained Asp-Silica was washed successively with water, $10 \%$ acetic acid and water again until neutral $\mathrm{pH}$.

Column Packing. Synthetic stationary phase was packed into $100 \times 4.6 \mathrm{~mm}$ I.D. stainless-steel columns under $40 \mathrm{MPa}$ pressure.

Preparation of Asp-Cu(II)-Silica Stationary Phase. Adopting dynamic chelate method, the packed Asp-Silica column $(100 \times 4.6 \mathrm{~mm}$ I.D. $)$ was connected to the chromatographic system, and then perfused with $50 \mathrm{mM}$ copper sulfate in $10 \mathrm{mM}$ $\mathrm{NaAc}-\mathrm{HAc}(\mathrm{pH} 5.0$ ) at the flow rate of $0.5 \mathrm{~mL} / \mathrm{min}$ until saturation. Unbound copper was washed out with water and $20 \mathrm{mM}$ $\mathrm{PB}$, successively (detection with $\mathrm{Na}_{2} \mathrm{~S}$ ).

Determination of Binding Capacity for Immobilized $\mathrm{Cu}^{2+}$. Copper ion (II) immobilized to metal chelate column was eluted with $50 \mathrm{mM}$ EDTA-2Na. The eluate was collected into $50 \mathrm{~mL}$ volumetric flasks and then diluted to the scale with water. Binding capacity of $\mathrm{Cu}^{2+}$ in the diluted eluate was determined by atomic absorption spectrophotometry (AAS) using EDTA-2Na as a blank solution.

Determination of Leakages for Immobilized $\mathrm{Cu}^{2+}$. The packed Asp-Cu(II)-Silica column $(100 \times 4.6$ mm I.D. $)$ was connected to the chromatographic system. Copper ion (II) immobilized to metal chelate column was eluted by gradient elution with the selected competitive systems. The eluate was collected into $50 \mathrm{~mL}$ volumetric flasks and then diluted to the scale with water. The leakage of $\mathrm{Cu}^{2+}$ in the diluted eluate was determined by AAS using competitive eluant as a blank solution.

Chromatographic Experiments. Effects of the $\mathrm{pH}$ of solution, the concentration of salt and immobilized metal ion on retention behavior of proteins, separation of protein mixtures on the columns were performed according to the chromatographic conditions given in Figures.

\section{Results and Discussion}

Ion Exchange Properties of Asp-Silica Stationary Phase.

Effect of pH Value on the Retention of Proteins: Effect of $\mathrm{pH}$ on the retention of proteins is a rather complicated issue, involving not only the electronegativity of stationary phase ligand but also the electronegativity of protein. ${ }^{13}$ To examine

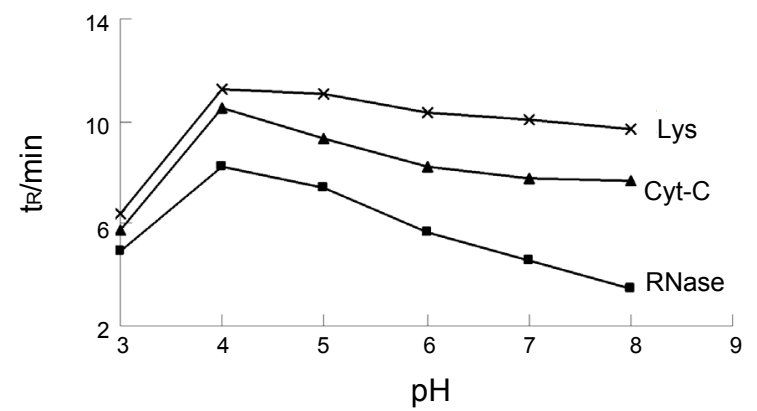

Figure 1. Effect of mobile phase $\mathrm{pH}$ on retention of proteins Column:

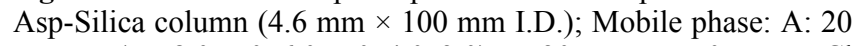
$\mathrm{mM}$ PB (pH 8.0, 7.0, 6.0, 5.0, 4.0, 3.0); B: $20 \mathrm{mM} \mathrm{PB}+0.5 \mathrm{M} \mathrm{NaCl}$ $(\mathrm{pH} 8.0,7.0,6.0,5.0,4.0,3.0)$; Gradient elution: $\mathrm{B}$ from 0 to $100 \%$ in $20 \mathrm{~min}$. Flow rate: $1 \mathrm{~mL} / \mathrm{min}$. Detector: UV $(\lambda=280 \mathrm{~nm})$. Size of sample: $5 \mu \mathrm{L}$.

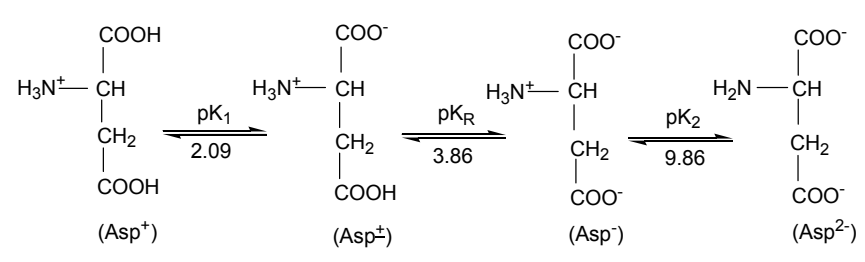

effect of $\mathrm{pH}$ on the retention of proteins, retention behaviors of three basic proteins on Asp-Silica column were investigated using gradient elution at a wide range of $\mathrm{pH} 3.0$ - 8.0. The results are presented in Fig. 1. It can be seen from Fig.1 that: (1) At pH 3.0 - 4.0, retention times of RNase, Cyt-C and Lys increased with the increase of $\mathrm{pH}$ values; However, retention times of three proteins decreased with the increase of $\mathrm{pH}$ values at the range of $5.0-8.0$. This is since L-Asp is a ternary weak acid $(\mathrm{pI}=2.97)$ and exists dissociative equilibrium at different $\mathrm{pH}$ values. The primary dissociation style of L-Asp without charge $\left(\mathrm{Asp}^{ \pm}\right)$is transformed into the secondary dissociation style with negative charge (Asp ${ }^{-}$) over the $\mathrm{pH}$ range from 3.0 to 4.0. The negative charge of the stationary phase increases rapidly resulting in the increase of electrostatic interactions between Asp and proteins with opposite charges. L-Asp mainly exists as the secondary dissociation style (Asp ${ }^{-}$) in the $\mathrm{pH}$ range from 5.0 to 8.0. The increase for the negative charge of Asp stationary phase is slower, and then the retention of proteins on Asp-Silica column mainly depends on the effect of $\mathrm{pH}$ on the positive charge of proteins. (2) At a certain $\mathrm{pH}$ value, the retention times of proteins on Asp-Silica column increased with the increase of $\mathrm{pI}$. This is since the positive charge of proteins increases with the increase of $\mathrm{pI}$, and then the electrostatic interaction between the negatively charged stationary phase and positively charged proteins increases.

Effect of Salt Concentration on the Retention of Proteins: The essence of gradient elution with salt in ion-exchange chromatography is static displacement between salt and adsorbed proteins on stationary phase ligand. If $L$ represents stationary phase ligand, $P$ is protein, $D$ is salt, $z$ is the ionic number of salt required for displacing one adsorbed protein molecular, there is an equilibrium between the protein adsorbed on stationary phase ligand $(L-P)$ and salt $(D)$ in solution as follows 


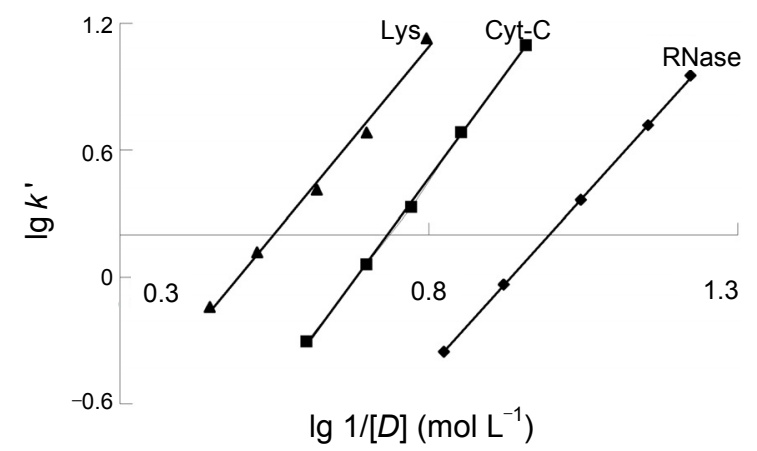

Figure 2. Effect of salt concentration on retention of proteins Mobile phase: $20 \mathrm{mM} \mathrm{PB}+\mathrm{X} \mathrm{M} \mathrm{NaCl}(\mathrm{pH} 6.0,0$ - 0.5 M). Isocratic elution. Other conditions are the same as in Fig. 1.
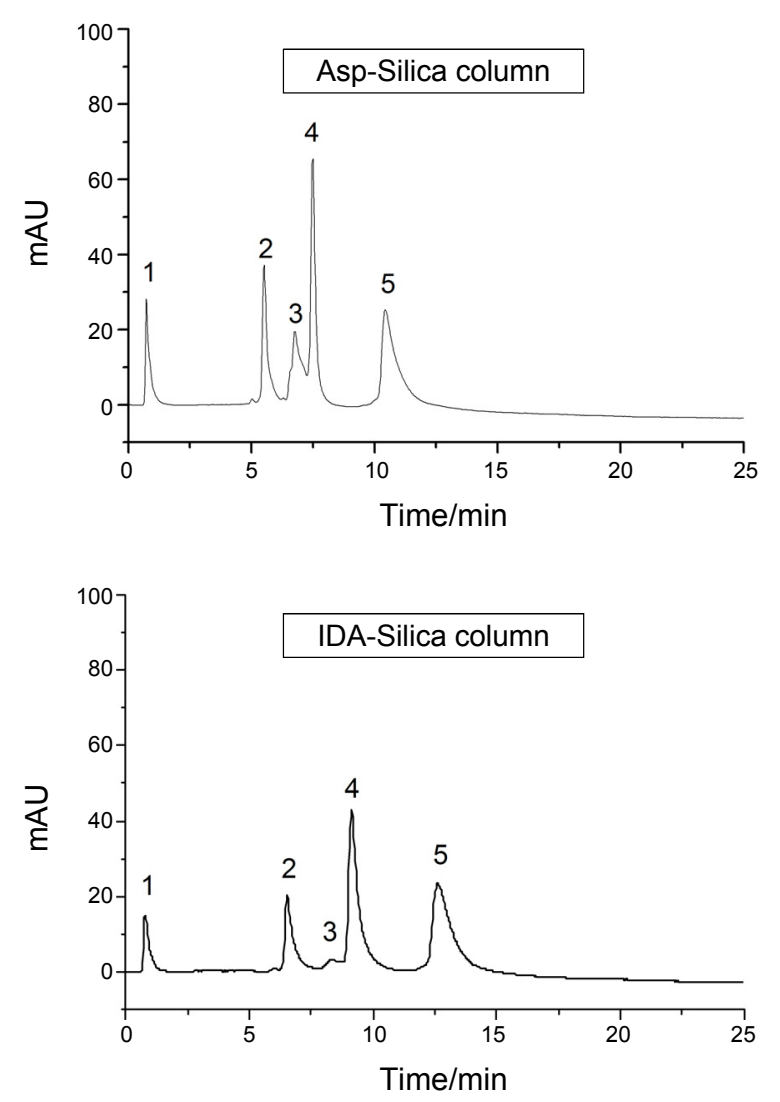

Figure 3. Chromatograms of protein mixture on Asp-Silica and IDASilica columns 1 . BSA; 2. RNase; 3 . impurity protein of cytochrome C; 4. Cyt-C; 5. Lys Mobile phase: A 20 mM PB (pH 6.0); B 20 mM $\mathrm{PB}+0.5 \mathrm{M} \mathrm{NaCl}(\mathrm{pH} 6.0)$. Other conditions are the same as in Fig. 1.

$$
L-P+z D=L-D_{z}+P
$$

If $k^{\prime}$ represents retention factor of protein on ion-exchange column, $\lg I$ is a constant related to properties and volumes of stationary phase and mobile phase, electrostatic interaction between stationary phase ligand and protein as well as salt, then the relationship between retention of protein on ion-exchange column and salt concentration should meet stoichiometric displacement theory (SDT-R), ${ }^{14}$ that is
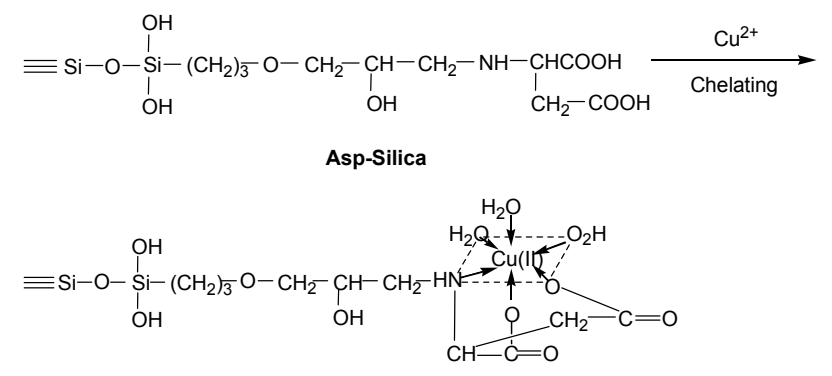

Asp-Cu(II)-Silica

$$
\lg k^{\prime}=\lg I+z \lg (1 /[D])
$$

To demonstrate the correctness of formula (1), retention values of three proteins on Asp-Silica column were determined by isocratic elution using $\mathrm{PB}$ with different salt concentrations. Fig. 2 is a plot of $\lg k^{\prime}(\log$ arithm of retention factor) $v s . \lg 1 /[D]$. As seen in Fig. 2, retention times of RNase, Cyt-C and Lys decreased with an increase in the concentration of $\mathrm{NaCl} \lg k^{\prime}-\lg$ $1 /[D]$ was well in linear relationship at a certain concentration range. Linear correlation coefficients were $0.9999,0.9997$ and 0.9953 , respectively. The results show that effect of salt concentration on the retention of proteins is consistent with SDT-R in ion-exchange chromatography. ${ }^{14}$

The above results show that the retention of protein on AspSilica column follows electrostatic interaction characteristic of cation-exchange.

Separation Comparison of Proteins on Asp-Silica and IDASilica Columns: To examine the separation performance of AspSilica column, standard protein mixture was separated with synthetic column using gradient elution, and the separation property of Asp-Silica column was compared with that of traditional IDA-Silica column. The results are presented in Fig. 3. As seen in Fig.3, four proteins were effectively isolated with prepared Asp-Silica column. Furthermore, adsorbed proteins on AspSilica column were eluted in the order of an increase in $\mathrm{pI}$ respectively, that is, acidic protein BSA (pI 4.9), basic proteins RNase (pI 8.7), Cyt-C (pI 10.1) and Lys (pI 11.0). This result once again demonstrated that synthetic Asp-Silica stationary phase had typical cation-exchange characteristics. In addition, the column efficiency and resolution of Asp-Silica were all superior to those of commonly used IDA-Silica column under the same chromatographic conditions.

Metal Chelating Properties of Asp-Cu(II)-Silica Stationary phase.

Effect of Immobilized $\mathrm{Cu}^{2+}$ on the Retention of Proteins: Adsorption of protein is occurred due to the coordination role of protein with immobilized $\mathrm{Cu}^{2+}$. When using competitive elution, chelate protein can be replaced by competitive agents such as Imid and Gly, and then adsorbed protein on metal chelating column is desorbed. Different proteins have the different affinities for $\mathrm{Cu}^{2+}$. In most cases, this difference can be used for the effective separation and purification of protein. ${ }^{15}$

Fig. 4 displays chromatograms of proteins on Asp-Cu(II)Silica and IDA-Cu(II)-Silica columns in PB-NaCl eluting system. As seen in Fig. 4, after immobilizing $\mathrm{Cu}^{2+}$ on the naked 

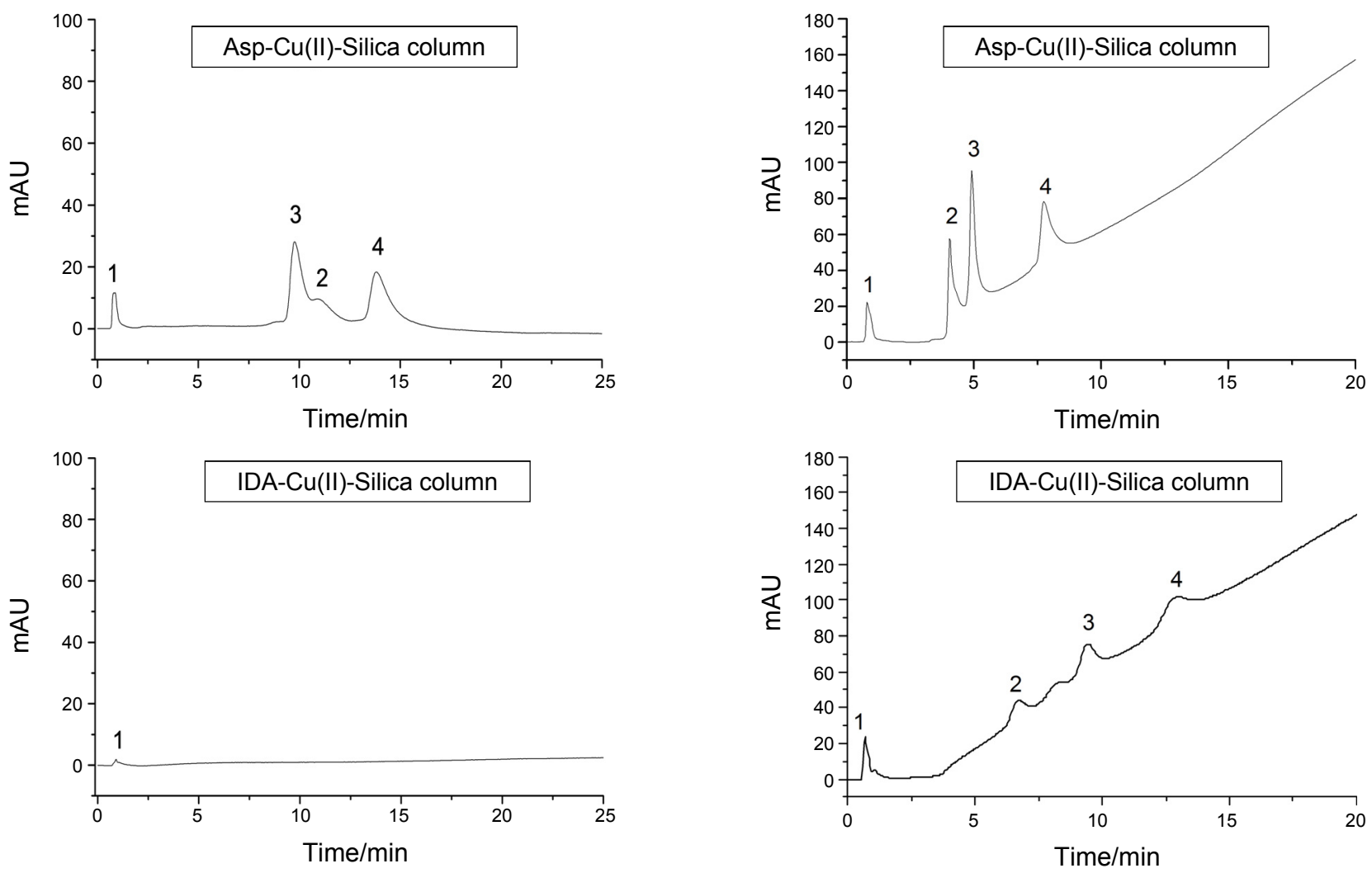

Figure 4. Chromatograms of protein mixture on $\mathrm{Asp}-\mathrm{Cu}(\mathrm{II})$-Silica and IDA-Cu(II)-Silica columns 1. BSA; 2. RNase; 3. Cyt-C; 4. Lys Chromatographic conditions are the same as in Fig. 3.

Asp-Silica column, the eluting capacities of $\mathrm{PB}-\mathrm{NaCl}$ for four proteins all significantly decreased. RNase and $\mathrm{Cyt}-\mathrm{C}$ were not separated, and the eluting order of these two proteins also changed. These are the results of coordination role between immobilizing $\mathrm{Cu}^{2+}$ and protein. In addition, four proteins on IDA$\mathrm{Cu}$ (II)-Silica column were hardly eluted. This shows that IDA$\mathrm{Cu}$ (II)-Silica column exhibited stronger coordination role with proteins as compared with Asp-Cu(II)-Silica column, proteins adsorbed on it could not easily be eluted.

Competitive Elution Comparison of Proteins on Asp-Cu(II)Silica and IDA-Cu(II)-Silica Columns: In addition to stationary phase, the choice of separation conditions is also important for metal chelate chromatography. Among these conditions, the type and concentration of competitive agents are particularly important because these conditions directly affect separation performance of chelating column and leakage of $\mathrm{Cu}^{2+}$ from chelating column. Fig. 5 displays chromatograms of proteins on Asp-Cu(II)-Silica and IDA-Cu(II)-Silica columns in competitive eluting system. As seen in Fig. 5, separation performance of Asp-Cu(II)-Silica column for proteins was better than that of IDA-Cu(II)-Silica column, four proteins on IDA-Cu(II)Silica column were hardly eluted. On the other hand, although the leakage of $\mathrm{Cu}^{2+}$ on IDA-Cu(II)-Silica column $(0.023 \pm 0.02$ $\mu \mathrm{mol} / \mathrm{mL}$ ) was slightly lower than that on Asp-Cu(II)-Silica column $(0.028 \pm 0.02 \mu \mathrm{mol} / \mathrm{mL})$ at the same chromatographic conditions, the eluting strength of proteins on IDA-Cu(II)-Silica

Figure 5. Chromatograms of protein mixture on $\mathrm{Asp}-\mathrm{Cu}(\mathrm{II})$-Silica and IDA-Cu(II)-Silica columns 1. BSA; 2. RNase; 3. Cyt-C; 4. Lys Mobile phase: A $20 \mathrm{mM} \mathrm{PB}+50 \mathrm{mM} \mathrm{NaCl}$ (pH 6.0); B $20 \mathrm{mM} \mathrm{PB}+0.5 \mathrm{M}$ $\mathrm{NaCl}+90 \mathrm{mM}$ Imid (pH 6.0). Other conditions are the same as in Fig. 1.

column was weak. This is because IDA is a stronger complexing agent, the stability constant of IDA with $\mathrm{Cu}^{2+}\left(\operatorname{lgk}_{\text {IDA-Cu (II) }}=\right.$ $10.62)^{16}$ is greater than that of L-Asp with $\mathrm{Cu}^{2+}\left(\operatorname{lgk}_{\mathrm{L}-\mathrm{Asp}-\mathrm{Cu}(\mathrm{III})}=\right.$ 8.57). ${ }^{17}$ Therefore, the bonding capacity of $\mathrm{Cu}^{2+}$ on IDA-Cu(II) column $\left(20.11 \mu \mathrm{mol} / \mathrm{g}_{\text {gel }}\right)$ was also higher than that of Asp$\mathrm{Cu}$ (II)-Silica column $\left(18.93 \mu \mathrm{mol} / \mathrm{g}_{\text {gel }}\right)$. Adsorbed proteins on IDA-Cu(II)-Silica column was difficult to be eluted in comparison with Asp-Cu(II)-Silica column. Consequently, the concentration of Imid should be increased in order to obtain efficient elution. However, the poor separation and high leakage of $\mathrm{Cu}^{2+}$ would be caused due to the increase in the concentration of Imid.

It follows that separating and eluting performances of metal chelate column should also be considered for the selection of ligand in addition to the stability of metal chelate column. The chelate with higher stability constant and bonding capacity with $\mathrm{Cu}^{2+}$ is not always the best choice of metal chelate ligand. The coordination intensity between the chosen ligand and immobilized $\mathrm{Cu}^{2+}$ should be moderated in order to ensure a less leakage of $\mathrm{Cu}^{2+}$, effective elution and separation of proteins on metal chelate $\mathrm{Cu}(\mathrm{II})$ column.

\section{Conclusion}

In summary, chosen L-Asp ligand had dual functions of cationexchange and metal chelate properties. At same time, separation and elution performances of Asp columns were all superior 
to those of traditional IDA columns, especially in the aspect of metal chelate property. These studies may provide certain reference values for the selecting and developing the aminocarboxy ligand with multifunction, improving the stability and elution performance of chromatographic column.

Acknowledgments. This work was supported by grants from Natural Science Foundation of Shaanxi Province (No. 2007 B22), Natural Science Fund of Shaanxi Provincial Education Department (N0. 09JK758), Shannxi Provincial Key Discipline Program and Scientific Research Foundation for the Master Program of Northwest University (No. 09YSY24). We thank to Ms Tan Hui of Xi'AN University of Architecture and Technology for the revision of the manuscript.

\section{References}

1. Josic, D.; Clifton, J. G. J. Chromatogr. A 2007, 1144, 2.

2. Gutierrez, R.; Del Valle, E. M. M.; Galan, M. A. Sep. Purif. Rev. $\mathbf{2 0 0 7}, 36,71$.

3. Geng, X. D.; Wang, L. L. J. Chromatogr. B 2008, 866, 133.

4. Helena, B.; Barbara, M.; Anne, S.; Nicole, B.; Jan, K.; Roland,
F.; Jörg, L.; Frank, S. Method. Enzymol. 2009, 463, 439.

5. Ding, M. Y.; Zheng, R.; Peng, H.; Chin, J. Anal. Chem. 2009, 37, 395.

6. Koen, S.; Mahan, M.; Filip, D.; Robin, T.; Katleen, V.; Koen, K.; Isabelle, F.; Pat, S. J. Chromatogr. B 2009, 877, 1019.

7. Li, R.; Wang, Y.; Chen, G. L.; Wang, X. G.; Zheng, J. B. Chromatographia 2009, 70, 731.

8. Jiang, W.; Mark, P.; Rodney, J. D.; Leone, S.; Milton, T. W. H. Biotechnol. Bioeng. 2009, 103, 747.

9. Steven, K.; Daniel, R.; Alex, N. E.; Beat, E. J. Mol. Recognit. 2009, 22,270

10. Alpert, A. J. J. Chromatogr. A 1983, 266, 23.

11. Ecaterina, S. D.; Maria, V. D.; Gabriela, L.; Andrzej, W. T. Eur. Polym. J 2009, 45, 2119.

12. Li, R.; Wang, Y.; Chen, G. L.; Shi, M.; Wang, X. G.; Zheng, J. Bull. Korean Chem. Soc. 2010, 31, 2201.

13. Van den Eijnden-van Raaij, A. J. M.; Koornneef, I.; Van Oostwaard, Th. M. J.; De Laat, S. W.; Van Zoelen, E. J. J. Anal. Biochem. 1987, 163, 263.

14. Geng, X. D. Stoichiometric Displacement Theory \& Application; Science Press: Beijing, 2004; pp 89-92.

15. Ueda, E. K. M.; Gou, P. W.; Morganti, L. J. Chromatogr. A 2003, 988, 1.

16. Sukalyan, S.; Arup, K. S. Environ. Sci. Technol. 1993, 27, 2133.

17. Foresti, M.; Luisa, L. N. J. Electroanal. Chem. 1989, 269, 41. 